\title{
TRABALHO E MODO DE VIDA: A EXPERIÊNCIA DOS OPERÁRIOS EM NOVAS ÁREAS INDUSTRIAIS
}

\author{
WORK AND LIFESTYLE: THE WORKERS' EXPERIENCE IN NEW INDUSTRIAL \\ AREAS
}

\author{
Izabel Cristina Ferreira Borsoi ${ }^{1}$
}

\section{Resumo}

O Nordeste tem sido um grande atrativo para fábricas, oriundas das regiões Sul e Sudeste, que buscam condições favoráveis à sua expansão - no caso, incentivos fiscais, infra-estrutura e força de trabalho de baixo custo. No Ceará, esse processo tem sido crescente principalmente a partir do início dos anos de 1990. O objetivo deste trabalho é discutir alguns aspectos do modo de vida de trabalhadores de fábricas instaladas em um município cearense que se desenvolveu a partir de um processo de industrialização favorecido pelas políticas do governo estadual. A discussão é fundamentada em um conjunto de entrevistas com trabalhadores e ex-trabalhadores de cinco dessas fábricas. Do que se pôde concluir, por um lado, os trabalhadores estão sendo submetidos a ritmos intensos, jornadas extensas e condições inadequadas de trabalho. Por outro, eles vêm construindo um novo modo de organizar a vida fora do trabalho, em função tanto do que vêm aprendendo quanto do que Ihes têm sido exigido nas dependências das fábricas onde trabalham. Entre outros aspectos, o conjunto de mudanças tem envolvido hábitos, valores e relações familiares e afetivas.

Palavras-chaves: Trabalhadores, modo de vida, fábricas.

\section{Abstract}

Northeast of Brazil has attracted many industrial enterprises from South and Southeast, which seek advantageous conditions for increasing - in that case, fiscal incitements, infrastructure, and inexpensive work force. In Ceará state, this process has been increasing particularly since the beginning of the ' $90 \mathrm{~s}$. This work intends to discuss some features of the lifestyle presented by workers employed in factories settled in a Ceará municipality, which developed based on an industrialization process supported by state government policies. The discussion is founded in a set of interviews with workers and ex-workers of five of those factories. On one hand, it was possible to conclude that workers have been submitted to work intensive rhythms, extensive days and improper conditions. On the other hand, it was found out that they are creating a new way of organizing their lives in the non-work time, due both to what they are learning and to what is required from them inside the factories. The current changes affect customs, values, and familiar and affective relationships, among others.

Key words: workers, lifestyle, factories. 


\section{INTRODUÇÃO}

Uma das estratégias do capitalismo contemporâneo para aumentar sua capacidade de produção tem sido buscar regiões pouco ou nada industrializadas que possam oferecer condições favoráveis tanto políticas quanto econômicas. Em se tratando da situação brasileira, tem se verificado o deslocamento de determinadas fábricas do Sul e Sudeste em direção ao Nordeste, aproveitando-se, geralmente, do que os governos estaduais possam oferecer como atrativos.

Entre os estados brasileiros que vem atraindo esses empreendimentos está o Ceará. Esse processo foi iniciado pelo Governo Tasso Jereissati que afirmava ter como objetivo de sua política industrial, definida pelo Plano das Mudanças para o período 1987-1991, "mudar o perfil industrial do Estado elevando o número de empregos diretos e indiretos e contribuindo para a melhoria dos níveis de renda da população" (RIGOTTO, 2001, p. 44).

As regiões que vêm absorvendo essas fábricas caracterizam-se pela carência de oportunidades de trabalho, pela ausência de tradição industrial e, a julgar pelo estudo de Pereira Jr. (2001), apresentam também características mais rurais que urbanas. Nesse caso, o processo de urbanização tem ocorrido concomitantemente ao processo de industrialização.

O tema que me proponho discutir neste texto diz respeito aos impactos que o processo de industrialização tem provocado no modo de viver de trabalhadores que não têm história de trabalho fabril em suas famílias². Pretendo desdobrar aqui, mais especificamente, alguns aspectos relativos à situação de trabalho vivenciada por eles nas fábricas e ao redimensionamento de seus hábitos, valores, e relacionamentos familiares e afetivos.

O cenário é um município localizado a 40 quilômetros de Fortaleza-CE, classificado como um dos menores do estado e qualificado como uma das maiores referências no que diz respeito ao processo de industrialização, sendo esta resultante da presença de uma abundante força de trabalho de baixo custo e, principalmente, da política de atração de capital industrial promovida pelo Governo do Estado. 
A instalação de fábricas provocou quase a duplicação do contingente populacional do lugar. Se em 1991 havia 18.283 habitantes, em 2000 a população saltou para 33.790, com 28.122 habitantes concentrados somente na área urbana. Em que pese isso, o município não perdeu sua face marcadamente rural em razão, fundamentalmente, da ausência de investimento em infra-estrutura urbana. Esse conjunto de características faz desse município uma "região nova" típica, palco das experiências de trabalhadores que, oriundos do meio rural, ingressam nas fábricas na esperança de encontrarem um trabalho mais ameno, rentável e capaz de propiciar um modo de viver mais suave e seguro.

Cabe aqui esclarecer sobre o que está sendo entendido por modo de vida e experiência. Modo de vida, nesse caso, não se refere apenas à forma como os trabalhadores conduzem seu cotidiano depois do trabalho, mas à experiência de vida do trabalhador, seja no trabalho, seja fora dele. Isto porque parto do princípio de que o modo de trabalhar tem relação intrínseca com o que ocorre na vida das pessoas depois de uma jornada de trabalho (BORSOI, 2005). Neste sentido, o trabalho é tomado como elemento fortemente constituidor, ou, no mínimo, organizador da vida social, familiar e psíquica.

Quanto à noção de experiência, ancoro-me em Thompson (1981), pois considero que as pessoas constroem sentidos sobre o que fazem e sobre a forma como vivem, trazem consigo sentimentos e certa capacidade de atuar sobre a realidade, considerando, obviamente, determinadas condições materiais e simbólicas nas quais estão inseridas.

Por fim, o tema abordado aqui está fundamentado em um conjunto de entrevistas com trabalhadores e ex-trabalhadores de cinco fábricas de médio e grande porte que, na ocasião, estavam entre as principais referências de trabalho na região em questão.

OS TRABALHADORES E AS FÁBRICAS

Pelo que relatavam os trabalhadores, a situação de trabalho nas fábricas pode ser caracterizada como, no mínimo, penosa, quando não muito 
insalubre. Guardando algumas diferenças entre uma fábrica e outra, em geral, as condições de trabalho são consideradas ruins por causa das temperaturas elevadas, da ausência de ventilação adequada, do ruído intenso, das máquinas, muitas vezes, perigosas, da presença de poeiras e de cheiros fortes de determinados produtos químicos. A jornada era sempre percebida como extenuante, não só por causa dos ritmos intensos, mas fundamentalmente pela excessiva exigência de horas-extras que podem chegar a quatro horas diárias, durante cinco dias por semana, dependendo da demanda em determinados períodos do ano.

Por tais condições de trabalho, esses trabalhadores recebem salários que geralmente ultrapassam pouco o salário mínimo vigente. Para, a maioria deles, os baixos salários podem ser justificados pelo fato de que "a empresa tem muito funcionário, então não pode pagar muito para todos". Diante disso, o único modo de aumentar o poder aquisitivo seria através do adicional por trabalho noturno ou por hora-extra, dos prêmios por produtividade e dos chamados "benefícios", a exemplo da cesta básica.

É esse contexto laboral que vai servir de divisor de águas entre um antes e um depois, o passado e o presente no que diz respeito não só ao trabalho, mas também às condições de vida desses trabalhadores. Antes das fábricas, a subsistência era garantida pelo trabalho no meio rural, nas fábricas de beneficiamento de castanha, nas granjas e em casas de farinha, no pequeno comércio ou ainda nas "casas de família", no caso das mulheres. As atividades normalmente eram qualificadas como muito penosas, com jornadas pouco definidas, remuneração incerta e muitas vezes irrisória. Era comum falarem da ausência dos chamados "direitos" como carteira profissional registrada, Fundo de Garantia por Tempo de Serviço (FGTS), previdência e determinados "benefícios".

Por causa do trabalho quase sempre incerto - geralmente realizado em condições muito penosas - e da remuneração insuficiente, a vida era qualificada também como extremamente penosa e carente de quase tudo: moradia, alimentação e vestuário adequados, acesso à saúde, à educação e ao lazer. 
É diante desse quadro que as fábricas surgem para esses trabalhadores como uma espécie de "tábua de salvação", pois oferecem a garantia de um trabalho formal que possibilita certo sentimento de segurança diante das tantas incertezas do então contexto de vida. "A vida mudou muito", "está muito melhor agora", estas eram expressões freqüentes para designar essa nova situação. Normalmente quando falavam de mudanças, referiam-se quase sempre ao que conseguem adquirir, a exemplo da pequena casa já construída ou em vias de ser adquirida, dos eletrodomésticos e eletroeletrônicos antes inimagináveis. Fora isto, há o fato concreto de que podem ter alimentação para todo o mês, que há condições de adquirir um ou outro medicamento numa farmácia ou num posto de saúde, caso algum familiar adoeça, que os filhos (quando os têm) podem freqüentar a escola pública do lugar, uma vez que julgam estar vivendo a urbanidade propiciada pelo que todos, orgulhosamente, consideram um "pólo industrial". Frente a esse novo momento da vida e ao fato de que, para esses trabalhadores, as fábricas estão oferecendo uma condição de trabalho bem menos penosa que a vivida anteriormente, as primeiras expressões para qualificarem o novo trabalho eram sempre carregadas de relativa positividade. Então, o "trabalho é bom", "gosto do que faço", "a fábrica X é ótima" eram maneiras comuns de se referirem à nova situação de trabalho. Com isso estavam se referindo ao fato de que há a certeza de uma jornada de trabalho definida a ser cumprida, alimentação dentro do próprio espaço de trabalho, a carteira profissional devidamente preenchida garantindo o direito ao FGTS, à previdência e ao seguro-desemprego, em caso de demissão. Além disso, em muitos casos, o chamado "quadro de benefícios" dessas empresas colabora de modo significativo no orçamento doméstico, a exemplo da cesta básica, do plano de saúde e dos "prêmios" por produtividade.

São esses os aspectos que fazem com que os trabalhadores vejam mudanças positivas tanto no trabalho que realizam quanto na vida fora dele. Aqui é preciso considerar que estão levando em conta dois momentos distintos do seu percurso de vida. De certa maneira, o sentido positivo que eles atribuem ao momento em que estão vivendo tem como referência um passado bastante 
recente de intensa carência material e social. Sendo assim, se comparado a tudo o que esses trabalhadores (não) tinham antes, o novo modo de viver está marcado por conquistas e mudanças muito significativas.

\section{O NOVO MODO DE VIVER: NOVOS HÁBITOS, VALORES E CONDUTAS EM CONSTRUÇÃO}

Entre as mudanças que os trabalhadores relatavam no novo modo de viver, há um conjunto de aspectos em processo de transformação que, nem sempre, eles próprios têm percebido de modo claro. Hábitos, valores, formas de relacionamento familiar e afetivo, representações do corpo e de si mesmos fazem parte de um conjunto de mudanças importantes decorrentes da inserção nas fábricas.

Um dos aspectos que chama a atenção é a re-configuração das relações familiares, envolvendo pais e filhos, homens e mulheres. Entre as famílias dos trabalhadores, a figura tradicional do chefe de família, normalmente personificada no pai, começa a perder, gradativamente, parte de suas atribuições. Como as fábricas procuram uma força de trabalho predominantemente jovem, com idade entre 18 e 35 anos, acabam excluindo as pessoas mais velhas da alternativa de trabalho mais promissora do lugar. Diante disso, os pais acabam, muitas vezes, transferindo a responsabilidade do orçamento doméstico para os filhos operários. Assim, mesmo que o pai continue formalmente reconhecido como "o chefe", são os filhos que, ao final, vêm determinando quanto e como empregar os rendimentos da família. São eles que, por deterem maior poder aquisitivo, passam a organizar 0 ambiente doméstico dotando-o de mais conforto. A autoridade dos pais parece prevalecer fundamentalmente por causa da condição de progenitores e não mais por serem provedores.

Se, por um lado, a posição de "chefe de família" vem sendo posta em questão, por outro, aspectos relacionados a papéis sociais de gênero começam também a tomar outros rumos, acentuando o impacto do trabalho fabril no ordenamento familiar. No que diz respeito às mulheres, suas atribuições têm 
aumentado e o comportamento, segundo algumas, até "mudou para melhor". Sair da rotina doméstica, compartilhar experiências de trabalho com outras pessoas em situação semelhante, submeter-se a tarefas rigidamente supervisionadas, gerir o próprio dinheiro são aspectos apontados como responsáveis para se perceberem diferentes. Para elas, a experiência do trabalho fabril tem forçado um processo de desinibição e de maior autonomia nas ações.

Para alguns desses trabalhadores, o novo trabalho vem oferecendo suporte para que a mulher possa "ser dona do mundo" - para adotar aqui a fala de um operário - na medida em que ela está se tornando mais independente. Isso se expressa na mudança da aparência, no maior investimento na estética corporal, no modo se vestir etc. Essa maior independência tem motivado até mesmo comentários jocosos em torno do comportamento de algumas mulheres. As histórias de sedução e traição eram freqüentemente relatadas, principalmente no caso de trabalhadoras da fábrica de calçado e, em alguma medida, também da fábrica de confecções, provavelmente por causa do maior contingente feminino. Separações entre casais de operários da mesma fábrica eram referências constantes; mulheres que deixam de trabalhar por se saberem traídas pelas próprias colegas ou, na linguagem corrente, "levaram chifre", também eram relatos comuns.

Em relação a essas transformações, homens e mulheres se dividem: entre os primeiros, alguns tendem a vê-las como positivas; entre as mulheres, entretanto, há, em geral, certa desconfiança. Mas, ao final, quase todos não se furtam a qualificar parte das mulheres, pelas histórias de sedução e traição, como "galinhas", "atiradas", "piranhas", "oferecidas", com isso sugerindo que elas são facilmente seduzíveis sexualmente por qualquer homem, independentemente de sua situação civil.

Um outro aspecto digno de nota, nesse processo, é a transformação de hábitos alimentares. Era opinião de quase todos os trabalhadores que o refeitório das fábricas não é o lugar mais indicado para uma alimentação saborosa. O que é servido, embora considerado bastante variado, normalmente desagrada ao paladar. "Comida ruim", "enjoenta", "sem gosto", "sem qualidade", "mal feita" são 
referências muito comuns. Sempre o que comem em casa era considerado mais saboroso, apesar da menor variedade. A maioria justificava que a comida da fábrica "é feita pra muita gente", razão porque "não tem gosto". Em casa, ao contrário, como "é pouca gente, a comida é sempre mais bem feita". Curiosamente, nem tudo na fábrica era considerado ruim. A feijoada, a carne assada ou frita, por exemplo, eram sempre elogiadas pelo sabor.

Diante disto, temos que buscar sentido para a "comida boa" e a "comida ruim" em outro lugar que não passe, necessariamente, pela noção de boa ou má qualidade do que é servido nessas fábricas. Pelo que afirmavam os trabalhadores, a alimentação costuma ser planejada por nutricionistas e, geralmente, não respeita os hábitos regionais. Neste caso, o que servem está mais de acordo com os que nutricionistas julgam necessário e adequado ao equilíbrio do corpo. Vale à pena mencionar uma frase dita por um operário que deixa claro o desagrado e também a descrença na qualidade nutricional da comida: "misturaram lá um bagaço, um picado de tomate com umas folha verde pra peão comer". Aqui é clara a alusão a uma alimentação pouco energética, insuficiente para satisfazer um indivíduo que precisa se haver com uma jornada intensa de trabalho.

Essa percepção de qualidade da alimentação é muito semelhante ao que Boltanski (1989, p. 154) identificou entre membros das "classes populares" na França, estando aí incluídas as famílias operárias. Pelo fato de estarem, geralmente, envolvidas em atividades para as quais era necessária a força física, as pessoas tendiam, entre outras coisas, a procurar "os alimentos tidos como 'nutritivos' e 'fortificantes', que 'sustentam', 'mantém o corpo', 'enchem', 'forram' ou 'revigoram', e cuja absorção, supõe-se que dê vigor e força". Nesse caso, as preferências alimentares recaiam sobre a chamada "cozinha pesada" composta de alimentos feculentos, carnes e gorduras.

Para os trabalhadores entrevistados, não só a comida propriamente dita é alvo de comentários, mas também a maneira de se comportar durante uma refeição. Eles relatavam que, em geral, lidar com talheres pela primeira vez dentro do refeitório das fábricas é quase sempre motivo de constrangimento. Isto porque em geral desconhecem a forma correta de empunhar garfo e faca, pois os hábitos 
que tinham incluíam mais comumente o uso da colher ou mesmo das mãos. Aprender a equilibrar algo sobre o garfo chega a ser, para alguns, tarefa tão difícil quanto manusear a máquina de trabalho pela primeira vez. A vergonha de não consegui-lo pode ser até motivo para "quase morrer de fome", como chegou a dizer uma trabalhadora.

Uma vez aprendidos, os novos hábitos precisam se estender ao cotidiano dos trabalhadores. Nesse caso, é necessário oferecer condições adequadas para que esse novo aprendizado seja praticado fora do ambiente laboral. Diante disso, uma das fábricas de maior referência da região, e também a que detém o maior número de trabalhadores, chama a atenção exatamente por, frequentemente, "brindar" seus trabalhadores, em datas festivas, com faqueiros, aparelhos de jantar, jogos de cama, mesa e banho. Em síntese, oferece a eles utensílios importantes para o reforçamento das chamadas "boas maneiras", já praticadas em suas dependências. Essa prática faz lembrar a política implementada por Ford no sentido de buscar formas de manter o controle sobre a vida privada dos trabalhadores para que eles pudessem se poupar para o trabalho em suas fábricas, conforme tão bem discute Gramsci (1978) em seu Americanismo e Fordismo.

No caso dos trabalhadores de nossa pesquisa, pelo que foi possível observar, eles ainda não têm adotado os novos hábitos no ambiente doméstico, a exemplo das "boas maneiras" à mesa. Isto porque, muitas vezes, se sentem constrangidos diante de suas famílias que continuam com os velhos hábitos. Assim, por enquanto, duas posturas ainda parecem se impor: na empresa, adotam, por exemplo, o garfo e a faca durante as refeições por vergonha dos colegas diante dos quais julgam necessário ostentar certa polidez; em casa, o uso da colher se mantém, pois "é esquisito" fugir ao padrão familiar. Isso poderia soar até mesmo como forma de esnobismo.

Diante do exposto, é possível afirmar que ainda é necessário que a racionalidade da fábrica deite suas raízes no cotidiano dos trabalhadores. Entretanto, o próprio fato de afirmarem a positividade dos novos costumes adquiridos já são indicativos importantes de esse é um processo que se encontra 
em construção. Os próprios trabalhadores afirmavam que aquilo que aprendem, de certo modo, já os prepara para situações sociais também fora do trabalho.

\section{CONSIDERAÇÕES FINAIS}

O que podemos notar nesta rápida exposição é que os trabalhadores buscam mostrar que existem ganhos importantes, não só no que diz respeito à melhoria das condições de vida, mas também no que se refere às mudanças que estão ocorrendo nas condutas, nos valores, nos hábitos etc. Aqui temos que considerar que se trata de um impacto significativo. Não sem razão, dizem que "a vida mudou muito" e "mudou para melhor". Aqui, é importante lembrar uma afirmação de Hobsbawm (1982, 140), ao se referir à parca melhoria da situação de vida da classe trabalhadora durante o período da "grande expansão do capitalismo", entre 1848 e 1875. Escreve o autor: "Era um quadro de pessoas com algum respeito e segurança, cujas expectativas eram enormemente modestas, mas conscientes de que poderia ser bem pior, que se lembravam de tempos quando eram bem mais pobres [...]".

Em que pese o reconhecimento de que há aspectos positivos percebidos pelos trabalhadores, cabe considerar também que eles continuam sob condições rígidas de trabalho e condições precárias de vida, que esse modo de viver só é percebido como positivo quando comparado ao que experimentavam antes.

Um outro aspecto importante a considerar é que não tem havido preocupação de instâncias governamentais, sejam elas estaduais ou municipais, em criar condições efetivas para que a região possa se tornar uma referência, de fato, de industrialização. No momento da pesquisa, o município contava com um sistema precário de saúde pública, não tinha saneamento básico e nem qualquer política de controle da poluição do solo, da água e do ar decorrente de resíduos industriais; também não havia sistema adequado de formação educacional e de qualificação para preparar trabalhadores para funções mais qualificadas oferecidas pelas fábricas. 
O que se pode notar é que os trabalhadores estão sendo, de alguma forma, preparados para a vida urbana - esta centrada em ritmos e costumes próprios dos lugares nos quais as fábricas são presença marcante. Estão experimentando um novo modo de viver, sem, no entanto, terem acesso aos recursos que possam efetivar até mesmo a positividade de determinados valores, hábitos e condutas que estão sendo, gradativamente, construídos.

Para finalizar, quero destacar que esse quadro não é uma peculiaridade de uma ou outra região, como tem sido observado no Ceará. Ao contrário, é uma situação que vem ocorrendo sistematicamente, e de modo generalizado, por causa da necessidade cada vez maior de expansão do capital na busca constante de maior lucratividade. O desafio aqui está, então, em encontrar formas de enfrentamento das conseqüências desse processo. Avalio que um debate amplo sobre essas questões, considerando as experiências dos próprios trabalhadores, é um passo importante, mas, obviamente, é apenas um ponto de partida.

\section{Referências bibliográficas}

BOLTANSKI, Luc. As Classes Sociais e o Corpo. Rio de Janeiro: Graal, 1989.

BORSOI, Izabel C. F. O Modo de Vida dos Novos Operários. Fortaleza: Editora da UFC, 2005.

GRAMSCI, Antônio. Americanismo e Fordismo. In: Obras Escolhidas. São Paulo: Martins Fontes, 1978, p. 311-339.

HOBSBAWM, Eric. A Era do Capital - 1848-1875. Rio de Janeiro: Paz e Terra, 1982.

PEREIRA JR., Edilson A. Industrialização e Reestruturação do Espaço: o caso de Horizonte-Pacajus (CE). 2001: 246 f. Dissertação (Mestrado em Geografia) Universidade Estadual do Ceará, Fortaleza.

RIGOTTO, Raquel M. Trabalho Industrial, Meio Ambiente e Saúde: discutindo aspectos da sustentabilidade do processo de desenvolvimento no Ceará. In: RIGOTTO, Raquel M. (Org.). As Tramas da (In)sustentabilidade: Trabalho, Meio Ambiente e Saúde no Ceará. Fortaleza: INESP, 2001, p. 33-63.

THOMPSON, E. P. A Miséria da Teoria ou um Planetário de Erros: uma crítica ao pensamento de Althusser. Rio de Janeiro: Zahar, 1981. 
${ }^{1}$ Professora do Departamento de Ciências Sociais da Universidade Federal do Espírito Santo e colaboradora do Programa de Pós-Graduação em Psicologia da Universidade Federal do Ceará. Email: cristinaborsoi@uol.com.br

${ }^{2}$ Este tema é desdobrado a partir da pesquisa para minha tese de doutorado intitulada $O$ modo de vida dos novos operários: quando purgatório se torna paraíso, publicada com o mesmo título pela Editora da UFC, em 2005. 